\title{
Determinants for the Growth of Stock Market
}

\begin{abstract}
Kapeel Dev ${ }^{1}$
Syed Farhan Shakeel ${ }^{2}$

Abstract

The stock market growth is interlinked with the economic growth and it is one of the most important pillar of the economy. The objective of this study is to examine the important determinants for the growth of stock market. The literature review suggests that many variables affect the growth of the stock market; some of them influence positively and some negatively. Therefore, four variables i.e. Size of the stock market, liquidity in the market, Foreign Investors' Portfolio Investment (FIPI) and Discount Rate (DR) have been focused in this where size of the market is dependent variable and remaining three are independent variables. Market capitalization (MC) is taken as proxy of size of the market wherein liquidity in the market is measured by the market volume $(M V)$. The results of regression analysis depicted the two variables i.e. FIPI and MV are the significant variables and are contributing positively towards the growth of the stock market, whereas DR is an insignificant variable. Therefore, it is concluded that the FIPI and MV are the most important factors for the growth of the stock market.
\end{abstract}

Keywords: Development, growth, stock market

\section{Introduction}

\subsection{Background of the Study}

The stock market is barometer of an economy and it plays a vital role in the economic growth and it is positively associated with economy. In the last 20 years worldwide financial markets more specifically the stock markets have been transformed drastically due to the emphasis given by the economic managers, which, ultimately, contributed positively towards the economic growth. The stock market in the countries like Pakistan is still in transition of developing phase; however, the developed countries stock markets have become more developed.

The stock market provides platform for raising funds and at the same time an opportunity to the investor. The company which requires financing may list their companies on the stock exchanges and offer its shares to the general public through Initial Public Offering (IPO) and the people invest in those companies by participating in the IPO. Subsequently, shares are available for trading at the stock exchanges. Therefore, stock exchange plays a role of intermediary, by bringing both financier and finance at the same platform. The securities and Exchange Commission of Pakistan (SECP) is the apex regulator of the capital market, hence all the IPOs are offered to general public after its approval.

There are three stock exchanges in Pakistan, Karachi Stock Exchange (KSE), Lahore Stock Exchange and Islamabad Stock Exchange (ISE). The stock exchanges in Pakistan are now demutualized, earlier, those were limited by guarantee. In terms of number of shares traded at the stock exchanges and market capitalization, $\mathrm{KSE}$ is the biggest and more active stock

${ }^{1}$ Kapeel Dev is Assistant Director, Securities Markets Division, Securities \& Exchange Commission, Pakistan, kapeel.dev@ secp.gov.pk ${ }^{2}$ Syed Farhan Shakeel is a former faculty member, SZABIST, Karachi.

\begin{tabular}{llll|l}
\hline JISR-MSSE & Volume 11 & Number 2 & July - December 2013 & 71
\end{tabular}


market in Pakistan, LSE is the $2^{\text {nd }}$ and ISE is the $3^{\text {rd }}$. The stock exchanges are being regulated by the SECP and its role is to safeguard the investors. In addition to this, other ancillary functions are being performed by National Clearing Company of Pakistan Limited (NCCPL) and Central Depository Company of Pakistan Limited (CDC). The NCCPL is responsible for the clearing and settlement of transactions carried out at the stock exchange and CDC performs the function of custodian of securities.

The performance of the stock market is interlinked with the fundamentals of the countries, the stock market can bring trickle down effect in the economy. The economic indicators boost the confidence of the local and foreign investors in the market and attract more foreign capital. One of the key elements to attract the foreign investment is the liquidity, so that investor can buy and sell the securities within minimum possible time. Other important factors to attract the foreign investors are the monitoring and surveillance of stock market activities and timely enforcement action by the regulator against the non-compliances of rules and regulations. Further more, the severe violations which may negatively affect the confidence of the investors are the price manipulations, insider trading and front running.

The stock market experienced two major crises in the last decade i.e., in 2005 and 2008 , which shattered the confidence of the local investors. However, KSE Index has moved up and touched its highest level in the history, whereas, the investors pursuing the growth as the artificial growth, hence movements of index and other correlated factors that contribute towards the growth of the market need to be assessed. Therefore, the study is focused on the variable impacting upon the growth by looking at both the perspective i.e., from the investors' point of view and the regulator's perspective.

\subsection{Research Objectives and Research Questions}

The objectives of the study are:

- To find out the relationship between the identified factors playing role in the growth of the stock market

- To find long run equilibrium between the identified factors playing role in the growth of the stock market

- To find the reliance of our market on the Foreign Investors portfolio investment and up-to what extent it lead the market

Taking the above stated objectives and the initial discussion into the consideration, this study focuse on the following questions:

- Does the liquidity bring positive impact on the stock market growth?

- Does FIPI affect the stock market positively?

- Does DR cause the stock market to move negatively?

\section{Literature Review}

A number of the researches were studied, which had derived number of variables such as liquidity in the market, new listing of capital, opportunity cost as the alternative investment option available to the investor with minimum level of risk i.e., Discount rate (DR), foreign 
investment, which are contributing towards the development of the stock market, macroeconomic stability in the country etc.

Aduda, Masila and Onsonge (2012) concluded that there are various macro-economic factors that are playing vital role in the development of the capital market, they concluded that stock market liquidity, institutional quality, bank development, per capita income and domestic savings are the key factors for the development of the stock market at the Nairobi Stock Exchange. In addition to this, they have further identified that the private capital flows, macro-economic stability and inflation has no relationship with the development of the stock market. Moreover, they have defined Institutional Quality as the bureaucratic system, democratic system and accountability that will ultimately attract the external finance.

Garcia and Liu (1999) studied the linkage between the development of the financial market and other associated variables i.e., financial reforms, country specific elements, macroeconomic variables and relationships between the various pillars of financial systems. They concluded that that there is positive relationship between development of the economy and the financial system, as the financial system grows the economy grows and vice versa. Similarly, Singh (1997) also suggested that there is positive association among the stock market development, economic growth. He linked the conclusions drawn in other studies related to the foreign Direct Investment (FDI) that FDI is very important factor for the capital inflow and it complements to domestic private investment (DPI), both ultimately create activity in the economic system, one side by investing in the economic system and creating jobs through which that start Spending and saving which add something in the system, further with that capital inflow the technologic at advancement take splace, that boost economic growth in the countries.

Another related study was done by Adam and Levine and Zervos (2001) identified three factors for the development of the stock market, which are size, liquidity and risk diversification. The size of the market is measured through the ratio of the market capitalization and GDP, the size of the market reflects the ability to mobilize the capital and provide more opportunities for diversifying the risk in better way, while, the second determinants as mentioned by Lervine and Zervos, the liquidity is measured through two ways, one is by dividing the value of the traded with GDP and second by dividing the values of trades with market capitalization, that actually measure the value of the equity market in comparison of the economy. Liquidity in the market attracts long term projects by promoting the acquisition the information regarding the firms and managers. Third, the diversification of risk is through investing in international markets, which diversify the systematic risk of the country, such political and economic risk.

Zervos and Levine (1998) transpired that there can be number of measures which are positively correlated with the stock market activity, which is also positively associated with the measures of real economic growth. In addition to that they emphasized that there can be more positive and strong association in the developing nations. Whereas, certain factors need to be constant or under the control, as the growth of the stock is positively related to economic growth, banking sectors growth, current and expected rate of growth, politic certainty which help in decision making by giving confidence in the consistency of the policy making.

Durham (2002), found out that the stock market development is more likely for the high income countries means developed countries rather for the developing countries. He further

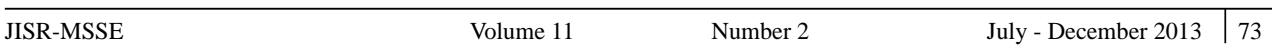


describes that as the higher income countries have the higher GDP per capita, higher level of development work, which attract more investments and higher income level countries have the low default risk as compared to other lower income countries. GirmaandShortland (2008) explained that the consistency in political system legal inception of the financial development, the study was conducted through Panel Data, the data has been taken from the developing and developed countries for the period from 1975 to 2000, the results depicted that degree of democracy and stability in the political system is playing a significant role in determining the financial system. Whereas, another study more recently conducted on the same subject matter of the determinants of the financial development in the year ended 2009 by the Habibullah, the data from the 27 countries have been taken and analyzed through panel for the period from 1980-2001 and concluded that quality of the institutions is playing a significant role in the development of the capital market and banking sector.

\section{Theoretical Framework}

The study is focused at determining the factors contributing towards the growth of the stock market, as the reviewed literature suggested various factors such as liquidity in the market, size of the market, risk diversification, strong regulatory framework, investor base, advancement in technology, new listing of capital in the market, political risk, default risk of the country and foreign investment. As per the time limitation and availability of the data, the study is restricted to only four variables, which are, Liquidity, Foreign Inventors Portfolio Investment ("FIPI") and risk free rate of return, the variables are discussed hereunder one by one.

\subsection{Variables}

\subsubsection{Size of the Stock Market}

In this study, the size of the stock market is a dependent variable, measured through the MC, which is the total value of the paid up capital of all the listed companies at the current trading price, it varies on the regular basis along with change in price of any scrip listed in the KSE.

\subsubsection{Liquidity in the Stock Market}

Liquidity is an independent variable, it reflects how fast an investor can buy or sell his holding in the market, and more liquid market will attract more investment due to less risk of offloading their investment, it also shows the confidence of the small investors in the market, if the MC is moving with no trading volume that will not lead towards the actual growth, then the said growth could be manipulative, it is always very easy to manipulate the stock which is very illiquid, therefore, the liquidity in the market is very much important for the growth of the market. The Liquidity in the market is measured through the turnover (MV) in the market.

\subsubsection{Foreign investors Portfolio Investment ("FIPI”)}

FIPI is also an independent variable; it is the investment by the foreign individuals and institutions in the stock market directly, it only focuses the investment in the stocks rather than investment in the companies.

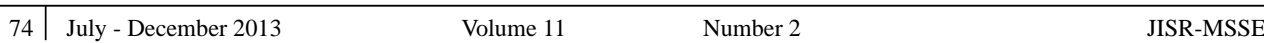




\subsubsection{Discount Rate ("DR")}

DR is an independent variable; it is the tool of monetary policy through which SBP controls the money supply in the market. The SBP announces discount rate currently after every two months, earlier it used ensurce in every four month by bidding through primary dealers and at the cut-off yield on the basis of money supply needed in the system. It is also called as Risk Free Rate, through which banks are used to lend and borrow the funds through discounting the T-Bills and PIB's.

\subsubsection{Relationship between the Variables}

MC is a dependent variable, however, MV, FIPI and DR are independent variables. Where, the literature suggested that some variables are positively linked and some are negatively associated with the growth of the stock market, here, two variables are FIPI and MV are contributing positively while one variable DR has negative relationship with stock market growth, it attracts the local investors and boost their confidence in the domestic stock market that ultimately leads to positive contribution in the market, however, the DR has negative association with the capital market, it is used as the alternative investment option, rise in the discount rate may bring negative impact on the stock market, as the investor may prefer to the risk free investment as those are promising higher returns, finally, the MV is the most important determinant for the growth of the market, it attracts both the local and domestic investor as it gives them the confidence that they can exit from the market any time, therefore, it add positively towards the stock market.

\subsection{Hypotheses}

H1: Market Volume positively impacts Stock Market Growth (MC)

H2: Foreign Investors Portfolio Investment impacts Stock Market Growth (MC)

H3: Discount Rate impacts Stock Market Growth (MC)

Figure1.

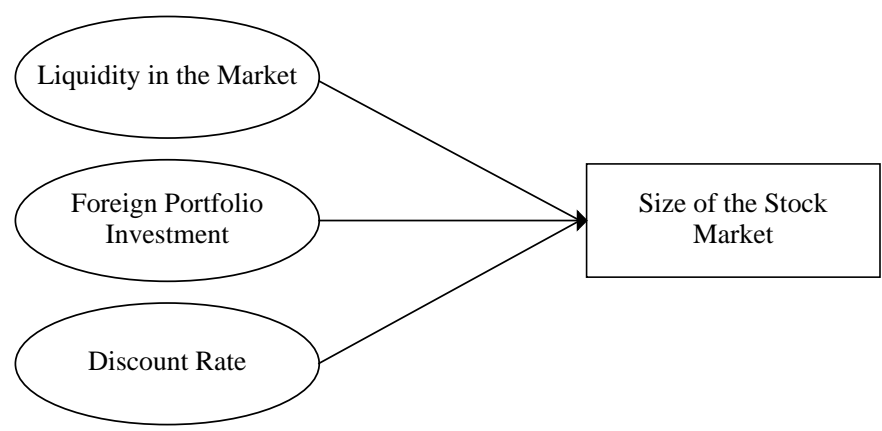

\section{Research Methodology}

The research is based on quantitative method, where it is being used to assess the parameters and significance of the variables and the movements and co-movements of the dependent variable with independent variable. The quantitative data is statistically examined through the Eviews 5. The data is analyzed descriptively and before evaluating the significance of 
the variables, the association among the variables is assessed. The regression analysis is applied to check the relationship among the variables and co-integration test is used to check the long run equilibrium of the variables.

This research is based on the secondary data, which is gathered on monthly basis for the period starting from January 2007 to December 2012, which covers 72 observations. The data has been collected from various sources, which include State bank of Pakistan ("SBP"), KSE, daily quotation of KSE and NCCPL and Bloomberg financial search engine. Market turnover is used as the proxy of liquidity in the market; here the total number of the shares traded during the month has been taken in the study.

\section{Data Analysis and Discussion}

The research is based on time series data. Therefore the main problem with the time series is stationarity of the data, in presence of the stationarity the result are spurious and misleading. The stationarity of the data is checked by applying the Augmented Dicky Fuller Test (ADF). The data is initially analyzed descriptively, thereafter regression and other statistically tests have been applied. The regression model is applied to check the relationship, impact and the significance of MC with other independent variables. The regression model is given below.

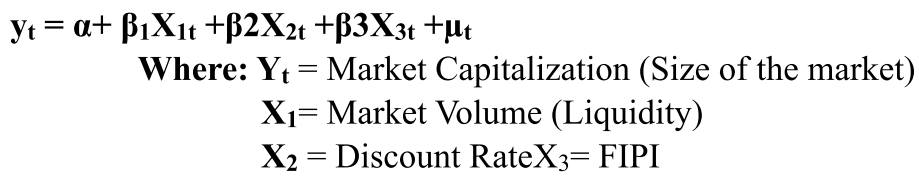

The analysis of the data has been done through Eviews version 05, where the inferences are drawn by applying various statistical tools. The analysis of the data is discussed hereunder one by one;

\subsection{Descriptive Statistics}

Data analysis generally begins with the calculation of a number of summarized statistics such as the mean, median, standard deviation, etc. The aim at this stage is to describe the general distributional properties of the data, to identify any unusual observations (outliers) or any unusual patterns of observations that may cause problems for later analysis to be carried out. The table 01 given in appendix shows the mean and standard deviation, Skewness and kurtosis of the variables. The descriptive analysis depicted that on average MC (size of the KSE) is Rs. 3.207 trillion, whereas, on average total 3.463 billion shares have been traded during the each month, that reflected that on average daily 157.439 million shares are being traded, further, on average the DR remained around $11.588 \%$.

The index of Skewness takes the value of zero for a symmetrical distribution. A negative value indicates a negatively Skewed distribution, a positive value shows positively skewed distribution. The kurtosis index measures the extent to which the peak of a unimodal frequency distribution departs from the shape of normal distribution. A value of 3 corresponds to a normal distribution; the value more than 3 indicate a distribution that is more pointed than a normal distribution and less than 3 or negative value indicate a flatter distribution. The

\begin{tabular}{l|llll}
\hline 76 & July - December 2013 & Volume 11 & Number 2 & JISR-MSSE
\end{tabular}


result shows that MC, MV, FIPI and DR are skewed distribution because the values of Skewness are positive for all the variables other than DR. MC is positive skewed because the Skewness value for MC is positive, only DR is negative skewed as the value of the

Table 1

\begin{tabular}{|l|c|c|c|c|}
\hline Variables & DR & FIPI & MC & MV \\
\hline Mean & 11.58818 & $4.37 \mathrm{E}+08$ & 3207879 & 3463.669 \\
Median & 11.93850 & $7.46 \mathrm{E}+08$ & 3090929 & 3163.110 \\
Maximum & 14.00580 & $1.07 \mathrm{E}+10$ & 4634771 & 8244.895 \\
Minimum & 8.814200 & $-11,800,000,000$ & 1700707 & 137.1600 \\
Std. Dev. & 1.645972 & $3.77 \mathrm{E}+09$ & 700184.7 & 1879.150 \\
Skewness & -0.4503314 & 0.66653 & 0.101729 & 0.624496 \\
Kurtosis & 1.886331 & 4.874850 & 2.593120 & 2.883875 \\
Jarque-Bera & 6.243338 & 12.61309 & 0.620839 & 4.720402 \\
Observations & 72 & 72 & 72 & 72 \\
\hline
\end{tabular}

\subsection{Unit Root Test}

A Stationary modeling is based on the assumption that the process is in a particular state of statistical equilibrium. A stochastic process is said to be strictly stationary if its properties are unaffected by a change of time origin. The Stationarity of the data is checked through applying ADF for the selection of lag length we used Schwartz criterion. applied ADF test applied on all the variables i.e. MC, DR, MV and FIPI position.

The null hypothesis of the therefore, Unit root test was applied at the level on all the variables to check the data stationary or non-stationary. The result obtained at the level shows that the $\mathrm{t}$-statistical (t-stats) value is lower than critical values (CR) at $1 \%$ for only FIPI, wherein, tstats is higher than CR in case of MC, DR and MV, therefore, the unit root test at the first difference was applied and results depicted that the t-stats value are more negative than critical values at $1 \%$, therefore, the null hypothesis is accepted of data non-stationary is rejected and the alternate hypothesis and concluded that the data is stationary at the first difference. The results are shown in table mentioned below:

Table 2

\begin{tabular}{|c|c|c|c|c|c|c|}
\hline \multirow{2}{*}{ Variable } & \multirow{2}{*}{$\begin{array}{c}\text { critical } \\
\text { value @ } \\
1 \%\end{array}$} & \multicolumn{2}{|c|}{ ADF on level } & \multirow{2}{*}{$\begin{array}{c}\text { critical } \\
\text { value @ } \\
1 \%\end{array}$} & \multicolumn{2}{|c|}{ ADF on first } \\
\hline & & t-stats & Prob & & t-stats & Prob \\
\hline $\mathrm{MC}$ & -3.525618 & -1.243966 & 0.6509 & -3.527045 & -8.023918 & 0.0000 \\
\hline MV & -3.525618 & 3.426211 & 0.0132 & -3.527045 & -9.007268 & 0.0000 \\
\hline FIPI & -3.525618 & -4.928269 & 0.0001 & -3.527045 & -11.31085 & 0.0001 \\
\hline DR & -3.525618 & -1.673231 & 0.4403 & -3.527045 & -6.632616 & 0.0000 \\
\hline
\end{tabular}




\subsection{Regression Analysis}

Regression is a technique to check the cause and effect of the independent on dependent variable, where, the coefficient are showing the direction and magnitude of the change caused in the dependent variable due to change in independent variable.

Goodness of Model: R2 is the goodness of fit; it measures the variations in dependent variable due to change in the independent variables of the model. On an overall basis, it shows the explanatory power of model. The table 10 shows the regression output, where, R-square is 0.564079 which shows that around $56.40 \%$ changes in MC are being explained by the explanatory variables i.e. MV, DR and FIPI. After adjusting the degrees of freedom, adjusted R Square reports a value of 0.545806 , showing that model has high explanatory power even accounting for

degrees of freedom.

F- Statistics: F-statistic is exercised to see the overall significance of the model, regression generated through Eviews depicted the probability value of $\mathrm{F}$ is 0.007063 which is significant at $1 \%$, therefore it is concluded that the specified model as a whole is statistically significant.

Durbin-Watson Statistics: Durbin-Watson statistics is used to check autocorrelation in the model, the standard value of Durbin Watson statistics is 2.0. Our regression model is reflecting value of Durbin Watson of 2.086757 that is near to 2, hence, it is considered in-line with the standard value of 2.00 and concluded that there is no autocorrelation in the specified model.

Coefficient and $p$ value: Coefficients of the independent variables show the cause and effect behavior of the independent and dependent variable. The Beta coefficient shows the direction and magnitude of the change in dependent variable with change in independent variable. If the coefficient is positive it means that the relationship between the dependent and independent variable is positive and if the coefficient is negative it means the relationship is negative. $P$ value and t- test check the significance of the independent variables on the basis of which we can reject or fail to reject null hypothesis. It is transpired from the table 3 that the DR has the negative co-efficient of Rs. -46474.16 which depicts that the DR negatively impacted the MC, i.e. one percent change in DR may cause on average change in the MC by 46.47 billion, while the t-stats value is insignificant, which shows that market capitalization on an average is insensitive to market behavior. If the DR is moving up or down, MC have no tendency to be influenced by this up or down move. The coefficient of the DR is statistically insignificant at 5\% significance level because the $\mathrm{p}$ value of the coefficient of market return $(0.4677)$ that is greater than 0.05 .

According to table 3 FIPI and MV have the positive effect with MC, as the coefficient value of the FIPI is 11858.33 which means that one percent increase in FIPI may lead to impact MC on average by Rs. 118.58 billion positively in Pakistan. The coefficient of the FIPI is statistically significant at $5 \%$ significance level because the $\mathrm{p}$ value of the coefficient of CPI (0.0255) is less than 0.05 . MV also has the positive relationship with MC, as the coefficient of the MV is 61.18505, which means that one percent positive change in MV may enhance MC by Rs. 61.185 billion on average. The coefficient of MV also is statistically significant because the $\mathrm{p}$ value $(0.0039)$ is less than 0.05 . 
Table 3

\begin{tabular}{|l|c|c|c|c|}
\hline Variable & Coefficient & Std. Error & t-Statistic & Prob. \\
\hline C & 17129.15 & 29176.26 & 0.587092 & 0.5591 \\
DRDIFF & -46474.16 & 63632.09 & -0.730357 & 0.4677 \\
FIPIDIF & 11858.33 & $7.61 \mathrm{E}-06$ & 1.551561 & 0.0255 \\
MVDIF & 61.18505 & 20.47565 & 2.988186 & 0.0039 \\
R-squared & 0.564079 & Mean dependent var & 16886.46 \\
\cline { 2 - 3 } Adjusted R-squared & 0.545806 & S.D. dependent var & 263034.9 \\
S.E. of regression & 245814.6 & Akaike info criterion & 27.71723 \\
Sum squared resid & $4.05 E+12$ & Schwarz criterion & 27.84471 \\
Log likelihood & -979.9617 & F-statistic & 4.383697 \\
Durbin-Watson stat & 2.086757 & Prob(F-statistic) & 0.007063 \\
\hline
\end{tabular}

\subsection{Co-integration Technique}

Co integration is when the two time series $\mathrm{y}$ and $\mathrm{x}$ are non-stationary and have a unit root, while following stochastic trend and their linear combination is stationary. Econometrically co-integration is used to test the relation among the variables, which is tested through EngleGranger (EG) test.

The co integration test transpired that where, trace statistic is significant and depicting that the at most two variables are significant at 5\% level of significance and there is at most two co-integration which evidences that there is long term equilibrium relationship between the two variables at $5 \%$ level of confidence. Lower part of the table is showing the Maximum Eigen value statistic, which also indicates that there is two co-integration at the 5 percent level of significance hence we concluded that there is long term equilibrium relationship between the variables. Thereby, the test implies that MC and all other variables MV, FIPI and DR have long run relationship as a whole.

Table 4

\begin{tabular}{|c|c|c|c|c|}
\hline $\begin{array}{l}\text { Hypothesized No. } \\
\text { of CE(s) }\end{array}$ & Eigenvalue & Trace Statistic & $\begin{array}{c}\text { Critical } \\
\text { Value } 0.05\end{array}$ & Prob.** \\
\hline None $*$ & 0.465000 & 107.3226 & 47.85613 & 0.0000 \\
\hline At most $1 *$ & 0.325325 & 64.78939 & 29.79707 & 0.0000 \\
\hline At most $2 *$ & 0.293580 & 38.02979 & 15.49471 & 0.0000 \\
\hline At most $3 *$ & 0.190806 & 14.39671 & 3.841466 & 0.1101 \\
\hline \multicolumn{5}{|c|}{$*$ Trace test indicates 4 cointegrating eqn(s) at the 0.05 level } \\
\hline $\begin{array}{l}\text { Hypothesized } \\
\text { No. of CE(s) }\end{array}$ & Eigenvalue & $\begin{array}{c}\text { Max-Eigen } \\
\text { Statistic } \\
\end{array}$ & $\begin{array}{c}\text { Critical } \\
\text { Value } 0.05\end{array}$ & Prob.** \\
\hline None $*$ & 0.465000 & 42.53317 & 27.58434 & 0.0003 \\
\hline At most $1 *$ & 0.325325 & 26.75961 & 21.13162 & 0.0072 \\
\hline At most $2 *$ & 0.293580 & 23.63308 & 14.26460 & 0.0013 \\
\hline At most $3 *$ & 0.190806 & 14.39671 & 3.841466 & 0.0901 \\
\hline
\end{tabular}

*Max-eigenvalue test indicates 4 cointegrating eqn(s) at the 0.05 level 


\section{Conclusion}

The study to explores the behavior and relationship between the variables impacting upon the stock market growth, thereby various econometrical tests were applied to check the significance of the parameters. Moreover, Market Capitalization has been used as the proxy to the stock market growth, market turnover was also used as proxy for liquidity in the market and discount rate was used on behalf of other alternative risk free investment, foreign investors' portfolio investment has been used for the foreign investment in the capital market. Econometric techniques, including the regressions and Co-integration along with the basic descriptive statistics, stationarity check through applying the Augmented Dicky Fuller Test for the period starting from January 2007 to December 2012. Therefore, the results transpired that FIPI is a significant variable reflecting that more foreign investment directly in the stock market contributing positively in the stock market and leading towards the growth of stock market by reflecting the trust of foreigners in our domestic capital market.

The t-stats value for the market volume was also significant and concluding that liquidity in the stock market adding positively in the stock market, as it gives more trust to the investors for free entry and exit in the capital market, which also attracts the foreign investment as well. The regression test applied overall concluded that the FIPI and MV have co-movements while DR does not co-move with the stock market growth. Moreover, co integration tests results revealed that at most two variables have the long run and significant relationship. It is concluded that stock markets are very much volatile and witnessed crash in the year 2008, that shattered the confidence of the investors due to which the volume in the stock market was decreased and FIPI was also decrease, that ultimately hit the stock market growth, it took lot of time to regain the confidence of the investor to come back and invest in the stock market. IT is further achieved that the increase in the market capitalization without rise in the market volume is also not genuine, that could be manipulative, until or unless the market volume enhanced in the market, the market cannot perform on the real basis.

\subsection{Recommendations}

On the basis of the findings of the study following points are needed to be accounted for in the model for in-depth understanding of market's behavior and strength:

- In addition to the market volume, Foreigner investor's portfolio investment and risk free rate, the study can be extended to sector index or specifically the scrip which have been given high weightage in the index, so that actual growth can be identified.

- The study is conducted on the monthly data only, it can be further extended to daily, weekly data, quarterly data and yearly data to better understand the behavior of the market movement and data has to be divided in the two part, one is pre market crash and other is post-market crash. 


\section{References}

Aduda, J., Mwelu, M. E. \& Nyakundi, O. (2012). The Determinants of Stock Market Development, Josiah International Journal of Humanities and Social Science, 2(9).

Claessens, S., Djankov, S., \& Klingebiel, D. (2001). Stock Markets in Transition Economies, Financial Sector Discussion of World Bank, 5.

Clayton, M. J., Jorgensen, B. N., \& Kavajecz, K. A. (1999), On the Formation and Structure of International Exchanges, The Stern School of Business New York University.

Domowitz, I., Glen, J., \& Madhavan, A. (2000). Liquidity, Volatility, and Equity Trading Costs across Countries and over Time, Pennsylvania State University.

Domowitz, I., Glen, J., \& Madhavan, A. (2002). International Evidence on Aggregate Corporate Financing Decisions, in Financial Structure and Economic Development, DemirgucKunt and Levine, (Eds.), (forthcoming) MIT Press.

Durham, J. B. (2002). The effects of stock market development on growth and private investment in lower-income countries. Emerging Markets Review, 211-232.

Dermirguc-Kunt, A., \& Levine, R. (1996). Stock market development and financial intermediaries, stylized facts, The World Bank Economic Review, 10. 291-321.

Dailami, M., \& Atkin, M. (1990). Stock Markets in Developing Countries: Key issues and a research agenda, Policy Research and External Affairs working Papers, the World Bank.

Errunza, V. R. (1983). Emerging markets - a new opportunity for improving global portfolio performance, Financial Analysts Journal, 39 (5), 51-58.

Girma, S., \& Shortland, A. (2008). The political economy of financial development. Oxford Economics Papers 60(4), 567-596.

Goldsmith, R. (1969), Financial structure and development, New Haven, Yale University Press.

Garcia, F., Valeriano, \& Lin L. (1999). Macroeconomic Determinants of Stock Market Development, Journal of Applied Economics, 2 (1), 29-59.

Levine, R. \& Zervos, S. (2001). Factors for the development of the stock market, World Economic Review 10, 323-340.

Levine, R., \& Zervos, S. (1998). Stock Markets, Banks, and Economic Growth, American Economic Review, 88, 537-558. 
Levine, R., \& Zervos, S. (1996). Stock market development and long-run growth, World Bank Economic Review, 10, 323-339.

Pagano, M. (1993). Financial markets and growth: an overview, European Economic Review, 37(2-3), 613-622.

Paul, G. (1992). Technological choice, financial markets and economic development, European Economic Review, 36, 738-781.

Reese, W. A. Jr., \& Weisbach, M. S. (2000). Protection of Minority Shareholder Interests, Cross-listing in the United States, and Subsequent Equity Offerings, Tulane University/University of Illinois

Singh, A. (1997). Financial liberalization, stock markets and economic development, The Economic Journal, 107, 771-82.

Sett, K., \& Sarkhel, J. (2010). Macroeconomic variables, Financial Sector Development and Capital Structure of Indian Private Corporate Sector.

Shaw, E. S. (1973), Financial Deepening in Economic Development, Oxford University Press.

Yartey, C. A. (2008). The Determinants of Stock Market Development in Emerging Economies: Is South Africa Different?, Washington: International Monetary Fund, 8(32). 